\title{
Co-Activation of Metabotropic Glutamate Receptor 3 and Beta-Adrenergic Receptors Modulates Cyclic-AMP and Long-Term Potentiation, and Disrupts Memory Reconsolidation
}

\author{
Adam G Walker ${ }^{1,2,5}$, Douglas J Sheffler ${ }^{3,5}$, Andrew S Lewis ${ }^{1,2}$, Jonathan W Dickerson ${ }^{1,2}$, Daniel J Foster ${ }^{1,2}$, \\ Rebecca K Senter ${ }^{1,2}$, Mark S Moehle ${ }^{1,2}$, Xiaohui Lv',2, Branden J Stansley ${ }^{1,2}$, Zixiu Xiang ',2, Jerri M Rook ${ }^{1,2}$, \\ Kyle A Emmitte ${ }^{1,2,4}$, Craig W Lindsley ${ }^{1,2,4}$ and P Jeffrey Conn ${ }^{*, 1,2}$ \\ 'Department of Pharmacology, Vanderbilt University, Nashville, TN, USA; ${ }^{2}$ Vanderbilt Center for Neuroscience Drug Discovery, Vanderbilt \\ University, Nashville, TN, USA; ${ }^{3}$ Cancer Metabolism and Signaling Networks Program, Conrad Prebys Center for Chemical Genomics, Sanford \\ Burnham Prebys Medical Discovery Institute, La Jolla, CA, USA; ${ }^{4}$ Department of Chemistry, Vanderbilt University, Nashville, TN, USA
}

\begin{abstract}
Activation of $\beta$-adrenergic receptors ( $\beta A R s$ ) enhances both the induction of long-term potentiation (LTP) in hippocampal CAI pyramidal cells and hippocampal-dependent cognitive function. Interestingly, previous studies reveal that coincident activation of group II metabotropic glutamate ( $\mathrm{mGlu}$ ) receptors with $\beta A R$ s in the hippocampal astrocytes induces a large increase in cyclic-AMP (cAMP) accumulation and release of adenosine. Adenosine then acts on $A_{1}$ adenosine receptors at neighboring excitatory Schaffer collateral terminals, which could counteract effects of activation of neuronal $\beta$ ARs on excitatory transmission. On the basis of this, we postulated that activation of the specific mGlu receptor subtype that mediates this response could inhibit $\beta$ AR-mediated effects on hippocampal synaptic plasticity and cognitive function. Using novel mGlu receptor subtype-selective allosteric modulators along with knockout mice we now report that the effects of $\mathrm{mGlu}_{2 / 3}$ agonists on $\beta A R$-mediated increases in cAMP accumulation are exclusively mediated by $m G$ lu $3_{3}$. Furthermore, $m G l u_{3}$ activation inhibits the ability of the $\beta A R$ agonist isoproterenol to enhance hippocampal LTP, and this effect is absent in slices treated with either a glial toxin or an adenosine $A_{1}$ receptor antagonist. Finally, systemic administration of the $\mathrm{mGlu}_{2 / 3}$ agonist LY379268 disrupted contextual fear memory in a manner similar to the effect of the $\beta A R$ antagonist propranolol, and this effect was reversed by the $\mathrm{mGlu}_{3}$-negative allosteric modulator VU0650786. Taken together, these data suggest that mGlu 3 can influence astrocytic signaling and modulate $\beta$ AR-mediated effects on hippocampal synaptic plasticity and cognitive function.

Neuropsychopharmacology (2017) 42, 2553-2566; doi:I0.1038/npp.2017.136; published online 23 August 2017
\end{abstract}

\section{INTRODUCTION}

Activation of noradrenergic projections from the locus coeruleus to the hippocampus and cortex enhances synaptic plasticity, aspects of cognition, and memory formation. Extensive studies suggest that noradrenergic regulation has a critical role in long-term retention of events that occur in novel environments or under conditions of mild stress. The majority of noradrenaline (NA) actions regulating hippocampal and cortical function are mediated through $\beta$-adrenergic receptors ( $\beta \mathrm{ARs}$ ). Interestingly, selective $\beta \mathrm{AR}$ agonists enhance induction of long-term potentiation (LTP) in hippocampal CA1 pyramidal cells and hippocampaldependent cognitive function (O'Dell et al, 2015).

\footnotetext{
*Correspondence: Professor PJ Conn, Department of Pharmacology, Vanderbilt University Medical Center, 1205 Light Hall, Nashville, TN 37232, USA, Tel: +6I5 936 2478, Fax: +6I5 343 3088,

E-mail: jeffrey.conn@vanderbilt.edu

${ }^{5}$ These authors contributed equally to this work.

Received 19 August 2016; revised 20 May 2017; accepted 14 June 2017; accepted article preview online 30 June 2017
}

Furthermore, hippocampal-dependent memory is impaired by reduced NA levels or $\beta \mathrm{AR}$ antagonists (Murchison et al, 2004; O'Dell et al, 2015).

A series of early studies revealed that $\beta A R$ coupling to adenylyl cyclase activation in hippocampal and cortical astrocytes is highly regulated by group II metabotropic glutamate ( $\mathrm{mGlu}$ ) receptors $\left(\mathrm{mGlu}_{2}\right.$ and $\left.\mathrm{mGlu}_{3}\right)$. Specifically, co-activation of $\beta$ ARs and group II mGlu receptors in astrocytes results in a marked potentiation of $\beta A R$-induced cyclic-AMP (cAMP) accumulation (Moldrich et al, 2002; Winder and Conn, 1993, 1995; Winder et al, 1996). This large increase in astrocytic cAMP under coincident $\beta$ AR and group II mGlu receptor activation has actions that could counteract the ability of neuronal $\beta$ AR activation to enhance synaptic plasticity. Specifically, the large increase in cAMP induced by co-activation of group II mGlu receptors with $\beta$ ARs leads to adenosine release from astrocytes and activation of presynaptic $A_{1}$ adenosine receptors on local excitatory SC terminals (Gereau et al, 1995; Winder et al, 1996). It has been hypothesized that this could serve as a mechanism to attenuate the physiological consequences of 
excessive excitatory transmission during periods of high noradrenergic activity, as would occur during periods of intense stress. However, $A_{1}$ adenosine receptor activation inhibits induction of LTP (de Mendonca and Ribeiro, 1994), and it is conceivable that activation of group II mGlu receptors could also reverse the ability of $\beta$ ARs to enhance induction of LTP. This is especially interesting in light of recent studies, suggesting that agonists and antagonists of group II mGlu receptors can, respectively, impair and enhance some forms of hippocampal-dependent cognitive function (Marek, 2010). On the basis of these studies, we postulated that the group II mGlu receptor subtype involved in this interaction with $\beta$ ARs could depress induction of hippocampal LTP under conditions in which $\beta$ ARs are also activated and could impair aspects of hippocampal-dependent learning that are sensitive to $\beta \mathrm{AR}$ activation.

We now report a series of studies using novel mGlu receptor subtype-specific allosteric modulators and knockout $(\mathrm{KO})$ mice to show that the $\mathrm{mGlu}_{3}$ receptor subtype is responsible for potentiating $\beta$ AR-elicited cAMP responses in brain slices. Furthermore, $\mathrm{mGlu}_{3}$ activation can block the enhancement of LTP by $\beta$ ARs by a mechanism that requires functional astrocytes and activation of $A_{1}$ adenosine receptors. Finally, we present evidence that $\mathrm{mGlu}_{3}$ activation can disrupt contextual fear memories in a manner that is similar to the effect of the $\beta \mathrm{AR}$ antagonist propranolol.

\section{MATERIALS AND METHODS}

\section{Materials and Chemicals}

LY379268, propranolol, CCPA, and PQ69 were purchased from Tocris (Ellisville, Missouri). MNI-137 (Hemstapat et al, 2007), BINA (Galici et al, 2006), VU0469942 (Wenthur et al, 2013), and VU0650786 (Engers et al, 2015) were synthesized as previously described. Unless otherwise stated, all other reagents were purchased from Sigma-Aldrich (St Louis, Missouri).

\section{Animals \\ All animal studies were approved by the Vanderbilt University Medical Center Institutional Animal Care and Use Committee and were conducted in accordance with the NIH Guide for the Care and Use of Laboratory Animals. Male Sprague-Dawley (SD) rats (Harlan Labs, Indianapolis, IN) aged 4-6 weeks were used for cAMP, electrophysiology, and immunohistochem- istry experiments. Male (age 32-38 days) ICR (CD1) mice (Harlan Labs) and $\mathrm{mGlu}_{2}$ or $\mathrm{mGlu}_{3} \mathrm{KO}$ mice and their wild- type (WT) littermates (Linden et al, 2005; used by permission of Eli Lilly and bred by Taconic Farms, Cambridge City, IN) were also used in cAMP studies. Behavioral experiments were conducted with male SD rats (Harlan Labs) ordered to arrive weighing $250-275 \mathrm{~g}$ and allowed to acclimate in the animal facility for 4-5 days before use.}

\section{Rodent Tissue cAMP Accumulation}

Agonist-induced increases in cAMP accumulation were measured in cross-chopped hippocampal or cortical slices prepared as previously outlined in detail (Gereau and Conn, 1994a). Slices were then incubated for $20 \mathrm{~min}$ with vehicle or $\mathrm{mGlu}_{2 / 3}$ agonists (LY379268) \pm the $\beta \mathrm{AR}$ agonist (isoproterenol (ISO)) before termination of the reaction and measurement of cAMP levels as previously described (Sheffler and Conn, 2008). Data were normalized to the percent vehicle cAMP response or the fold-over basal cAMP response where appropriate as indicated. Concentration-response curve data were fit using Prism 5.0 (GraphPad) to a four-parameter logistic equation to determine $\mathrm{EC}_{50}$ or $\mathrm{IC}_{50}$ values. Significance was determined using Prism 5.0, performing a one-way ANOVA followed by a Bonferonni post-test unless otherwise noted.

\section{Hippocampal Slice Preparation for Electrophysiology}

Rats were anesthetized with ketamine $(100 \mathrm{mg} / \mathrm{kg}$ intraperitoneal (I.P.)) and xylazine (10 mg/kg I.P.) and perfused with $4{ }^{\circ} \mathrm{C}$ sucrose-based cutting buffer containing (in mM): 230 sucrose, $2.5 \mathrm{KCl}, 10 \mathrm{MgCl}, 0.5 \mathrm{CaCl}_{2}, 1.25 \mathrm{NaH}_{2} \mathrm{PO}_{4}, 10$ glucose, $26 \mathrm{NaHCO}_{3}$, and 0.5 sodium ascorbate. Horizontal hippocampal slices $(400 \mu \mathrm{m})$ were prepared with a vibrating microtome (VT1200s, Leica), incubated $12-15 \mathrm{~min}$ at $32{ }^{\circ} \mathrm{C}$ in an N-methyl-D-glucamine-based recovery solution (Walker et al, 2015), and transferred to a holding chamber with artificial cerebrospinal fluid (aCSF) containing (in $\mathrm{mM}$ ): $126 \mathrm{NaCl}, 2.5 \mathrm{KCl}, 1 \mathrm{MgCl}, 2 \mathrm{CaCl}_{2}, 1.25 \mathrm{NaH}_{2} \mathrm{PO}_{4}, 15$ glucose, $26 \mathrm{NaHCO}_{3}$, and 5 sodium ascorbate. Recording aCSF was identical minus ascorbate.

\section{Extracellular Field-Potential Recordings}

Field excitatory postsynaptic potential (fEPSP) and LTP recordings were performed as previously described in detail (Noetzel et al, 2013). The adenosine $\mathrm{A}_{1}$ receptor antagonist 8-cyclopentyltheophylline (CPT) was bath-applied for $10 \mathrm{~min}$ (200 nM; Schmitt et al, 2012) before beginning experiments. Sodium fluoroacetic acid (FAC) was bathapplied after a 5-min baseline period. We found that on average fEPSP slopes stabilized $15 \mathrm{~min}$ after FAC exposure. Slopes were normalized to the average from 20 to $30 \mathrm{~min}$ from the start of the recordings and drug applications began at $30 \mathrm{~min}$. Data were analyzed as previously described (Walker et al, 2015). Statistical comparisons between drug conditions were made using unpaired $t$-tests, one-way or two-way ANOVA as appropriate followed by Tukey post hoc tests. See Supplementary Materials for NMDA current measurement methodology.

\section{Imaging}

See Supplementary Methods for immunohistochemistry details.

For RNAscope combined with immunohistochemistry experiments, slices were washed three times in $1 \times \mathrm{TBS}$ after sectioning. To perform RNAscope with traditional immunohistochemistry, the manufacturer's directions (Advanced Cell Diagnostics (ACD)) were modified. After washing, sections were incubated in $95^{\circ} \mathrm{C}$ pre-warmed ACD antigen retrieval buffer for $15 \mathrm{~min}$, and then immediately washed three times in $1 \times$ TBS. After washing, sections were mounted to positively charged glass slides (ThermoFisher, 
New York, NY) and dried overnight. Once dry, a hydrophobic barrier was placed around the section and dried for $1 \mathrm{~h}$ at $60^{\circ} \mathrm{C}$. The following steps were performed at $40^{\circ} \mathrm{C}$ in an ACD HybEZ slide hybridization oven (Newark, CA). First, slides were incubated in ACD protease IV for $15 \mathrm{~min}$ and then washed $3 \times$ in ACD RNAscope wash buffer. Slides were then incubated with anti-ADRB2 and anti-GRM3 probes for $2 \mathrm{~h}$ and then washed $3 \times$ in $A C D$ RNAscope wash buffer. After hybridization with probes, slides were hybridized with Amp 1-FL for $30 \mathrm{~min}$, with Amp 2-FL for $15 \mathrm{~min}$, with Amp 3-FL for $30 \mathrm{~min}$, and then Amp 4 FL-A for $15 \mathrm{~min}$, with three RNAscope wash buffer washes between each hybridization. After RNAscope staining was completed, slides were blocked in $10 \%$ normal donkey serum with $0.1 \%$ Triton X-100 in $1 \times$ TBS for $1 \mathrm{~h}$ at room temperature and then washed two times for $5 \mathrm{~min}$ in $1 \times$ TBS. After blocking, slides were incubated with $1: 100$ goat anti-GFAP (Abcam, Cambridge, UK) in $10 \%$ normal donkey serum for $24 \mathrm{~h}$ at $4{ }^{\circ} \mathrm{C}$ and then washed two times for $5 \mathrm{~min}$ in $1 \times \mathrm{TBS}$. After primary incubation, slides were incubated with 1:500 donkey anti-goat-Cy3 (Jackson Immuno-Research, West Grove, PA) for $2 \mathrm{~h}$ at room temperature, and then washed three times in $1 \times$ TBS. Slides were air-dried and mounted in pro-long goldmounting media (Life Technologies, Grand Island, NY). Slides were imaged on a Zeiss LSM 510 inverted confocal microscope.

\section{Contextual Fear Conditioning}

Contextual fear-conditioning experiments were performed similar to previous reports (Taherian et al, 2014; see Supplementary Methods for details of behavioral training). We tested the effects of vehicle, propranolol $(10 \mathrm{mg} / \mathrm{kg})$, LY379268 (1-3 mg/kg), VU0650786 (56.6 mg/kg), CCPA $(0.1-0.15 \mathrm{mg} / \mathrm{kg}), \quad$ PQ69 $\quad(0.3-1.0 \mathrm{mg} / \mathrm{kg})$, a mixture of LY379268 and VU0650786 or LY379268 and PQ69 on reconsolidation and/or consolidation. Propranolol, LY379268, CCPA, and PQ69 doses were based ranges in previously published studies showing efficacy in vivo (Concas et al, 1993; Lu et al, 2014; Pitsikas and Markou, 2014; Taherian et al, 2014). VU0650786 dosing was selected based on our extensive previous in vivo studies (Engers $e t$ al, 2015). All compounds for behavioral experiments were formulated with $10 \%$ Tween 80 in sterile water and the $\mathrm{pH}$ was adjusted to 7.4 with $\mathrm{NaOH}$ and injected at a volume of $2 \mathrm{ml} / \mathrm{kg}$. Drug conditions were compared with a one-way ANOVA. Post hoc comparisons for significant omnibus tests were performed using a Dunnett's multiple comparison test $v s$ vehicle.

\section{RESULTS}

\section{Group II mGlu Receptor-Induced Potentiation of $\beta$ AR-Mediated cAMP Accumulation is Mediated by $\mathrm{mGlu}_{3}$}

We previously reported that coincident activation of group II mGlu receptors and $\beta$ ARs leads to robust increases in cAMP accumulation in a variety of rat brain regions including the cortex and hippocampus (Winder and Conn, 1993; Winder et al, 1996). However, the group II mGlu receptor subtype mediating this effect is unknown. In order to investigate the contribution of the individual group II mGlu receptor subtypes, we took advantage of two pharmacological tools that exhibit $\mathrm{mGlu}_{2}$ and $\mathrm{mGlu}_{3}$ subtype selectively. First, we confirmed that co-activation of $\beta$ ARs and group II mGlu receptors results in enhanced cAMP accumulation in brain slices. As shown in Figure 1a and c, application of the $\mathrm{mGlu}_{2 / 3}$ agonist LY379268 (100 nM) significantly potentiates cAMP accumulation induced by the $\beta$ AR agonist ISO $(10 \mu \mathrm{M})$ in slices from both rat hippocampus $\left(\mathrm{F}_{(7,16)}=5.369, p<0.05\right.$; Bonferonni post-test $\left.p<0.05\right)$ and mouse cortex $\left(\mathrm{F}_{(7,16)}=5.819, p<0.05\right.$; Bonferonni post-test $p<0.05) v s$ vehicle. When slices were pre-incubated with the $\mathrm{mGlu}_{3}$-negative allosteric modulator (NAM) VU0469942 $(10-30 \mu \mathrm{M})$, there was a concentration-dependent decrease in cAMP accumulation, whereby the response to LY379268 plus ISO was not statistically different from vehicle in the presence of VU0469942 ( $p>0.05)$.

In order to evaluate the contribution of $\mathrm{mGlu}_{2}$ to this biochemical response, we characterized the effects of the $\mathrm{mGlu}_{2}$-selective positive allosteric modulator (PAM) BINA on the dose-response of a group II agonist-induced potentiation of $\beta$ AR-mediated cAMP responses. As shown in Figure $1 \mathrm{~b}$, the $\mathrm{mGlu}_{2 / 3}$ agonist LY379268 dose-dependently potentiated ISO-induced cAMP responses in rat hippocampal slices. However, pretreatment of the slices with $1 \mu \mathrm{M}$ BINA does not alter the LY379268 dose-response (no difference in LY379268 potency or maximal response; $p>0.05)$. This concentration of BINA $(1 \mu \mathrm{M})$ has near-maximal potentiating effects on $\mathrm{mGlu}_{2}$-mediated responses in cell lines and in hippocampal slices (Galici et al, 2006). Nevertheless, we determined the effect of an even higher concentration of BINA $(10 \mu \mathrm{M})$ on the dose-response of LY379268 for potentiation of ISO-induced cAMP responses in ICR (CD1) mouse cortical slices (Figure 1d). Similar to the effects in rat hippocampal slices, BINA does not potentiate the LY379268 doseresponse in mouse cortical slices (no difference in LY379268 potency or maximal response; $p>0.05$ ). Together, these studies suggest that $\mathrm{mGlu}_{3}$ is likely the primary group II mGlu receptor subtype that potentiates $\beta$ AR-mediated cAMP responses.

We next evaluated group II mGlu receptor-mediated potentiation of effects of $\beta A R$ activation on cAMP accumulation in cortical slices prepared from $\mathrm{mGlu}_{2}$ and $\mathrm{mGlu}_{3} \mathrm{KO}$ mice and their matched WT littermate pairs. As shown in Figure 1e and f, $100 \mathrm{nM}$ and $1 \mu \mathrm{M}$ LY379268 potentiated ISO-induced cAMP responses in cortical slices prepared from the WT littermates for either the $\mathrm{mGlu}_{2}$ $\left(\mathrm{F}_{(8,27)}=32.39, p<0.05 ;\right.$ Bonferonni post-test $p<0.05$ vs vehicle) or $\mathrm{mGlu}_{3}\left(\mathrm{~F}_{(8,27)}=10.15, p<0.05\right.$; Bonferroni posttest $p<0.05 v s$ vehicle) KO mice, and these effects are blocked by the $\mathrm{mGlu}_{2 / 3}$ NAM MNI-137 ( $p>0.05 v s$ vehicle). Furthermore, the group II mGlu receptor agonist potentiated $\beta$ AR cAMP responses in cortical slices prepared from $\mathrm{mGlu}_{2} \mathrm{KO}$ mice (Figure 1g; $\mathrm{F}_{(8,27)}=10.15, p<0.05$; Bonferroni post-test $p<0.05$ vs vehicle). In contrast, LY379268 had no effect on ISO-induced increases in cAMP accumulation in slices from $\mathrm{mGlu}_{3} \mathrm{KO}$ mice (Figure $\mathrm{lh}$; $\mathrm{F}_{(8,27)}=39.25, p<0.05$; Bonferroni post-test $p>0.05$ for ISO + LY379268 vs vehicle). The absence of a cAMP potentiation response in $\mathrm{mGlu}_{3}$ but not $\mathrm{mGlu}_{2} \mathrm{KO}$ mouse cortical slices is 
consistent with the pharmacological studies and further confirms that $\mathrm{mGlu}_{3}$ mediates potentiation of $\beta \mathrm{AR}$-induced cAMP responses. It should be noted that there appears to be a blunted cAMP potentiation in WT littermates for the $\mathrm{mGlu}_{2} \mathrm{KO}$ mice. This effect was consistently observed in the process of performing these experiments.

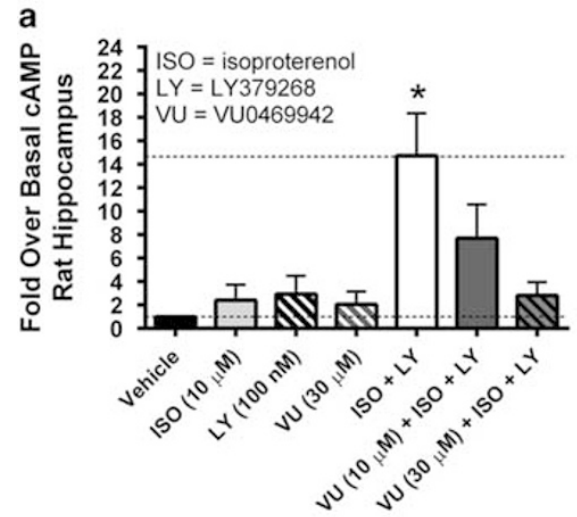

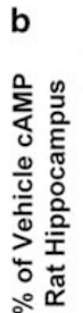
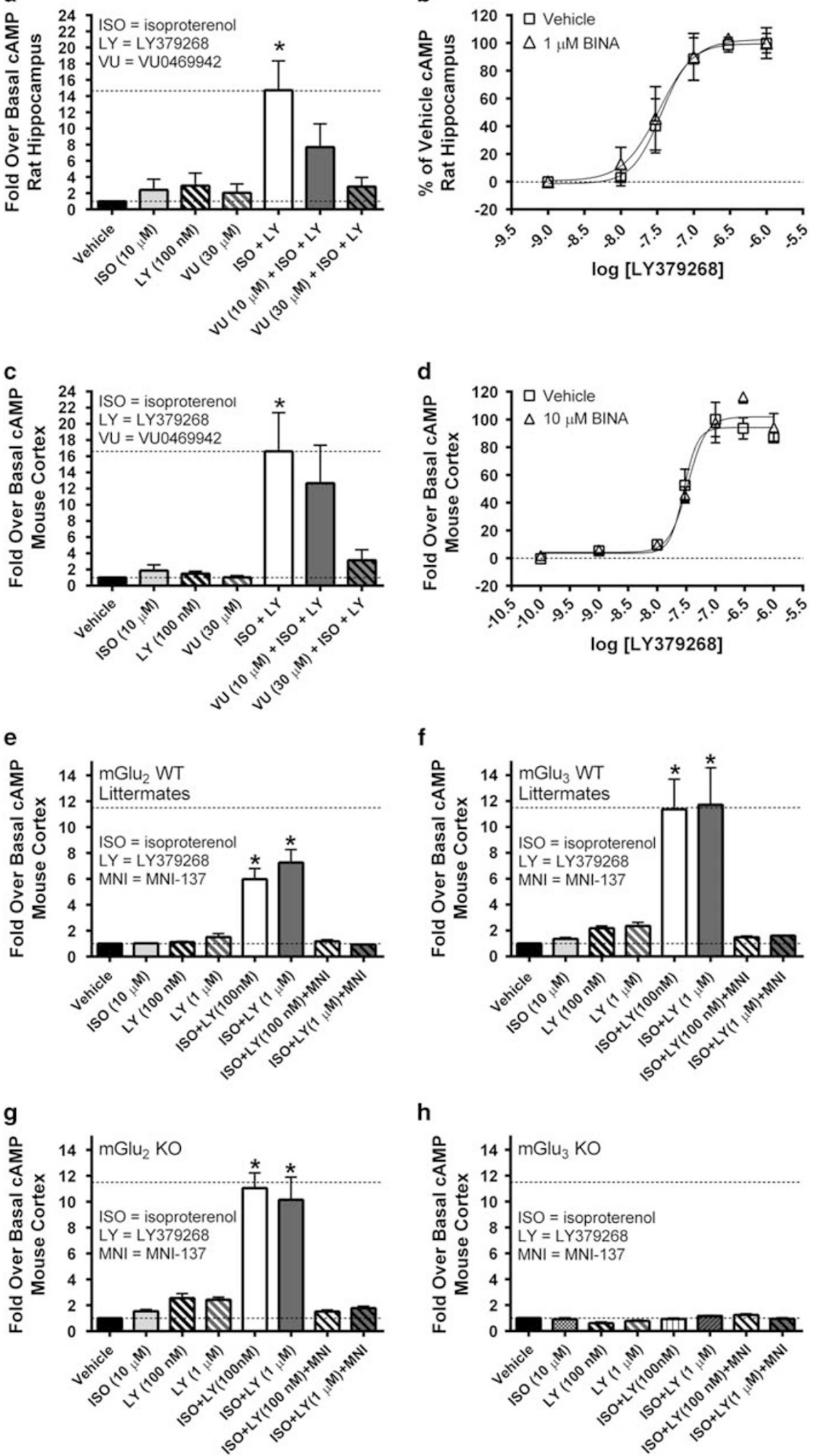

h

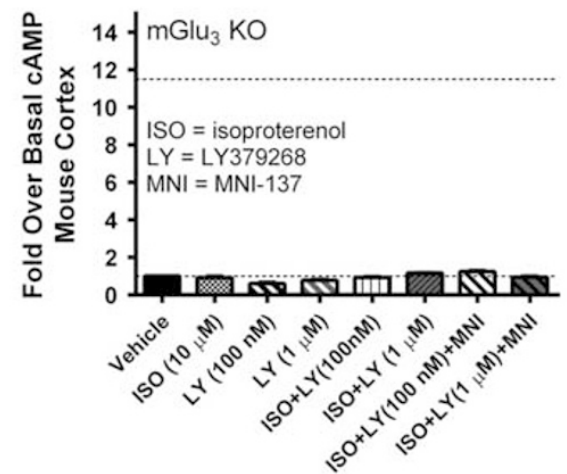


Unfortunately, we do not currently have an explanation for this phenomenon.

\section{mGlu $_{3}$ Activation Antagonizes the Enhancing Effects of $\beta A R s$ on Theta Burst-Induced LTP at the SC-CA1 Synapse}

An important function of $\beta \mathrm{AR}$ activation in area CA1 is to enhance the ability of weak afferent stimulation patterns to induce LTP at the SC-CA1 synapse through actions on CA1 pyramidal cells (O'Dell et al, 2015). On the basis of previous findings that the large increase in cAMP accumulation induced by coincident activation of $\mathrm{mGlu}_{2 / 3}$ and $\beta$ ARs on astrocytes leads to release of adenosine and activation of $A_{1}$ adenosine receptors on SC terminals (Gereau et al, 1995; Winder et al, 1996), we sought to determine whether group II mGlu receptors can inhibit the ability of $\beta \mathrm{AR}$ activation to enhance hippocampal LTP at the SC-CA1 synapse. We recorded extracellular fEPSPs at the SC-CA1 synapse in hippocampal slices prepared from rats. LTP was induced using two different theta burst stimulation (TBS) protocols (Figure 2a) to induce increasing levels of potentiation of excitatory transmission. As shown in Figure $2 b$, the weak TBS protocol results in an increased fEPSP slope $(148.3 \pm 8.3 \%)$ vs baseline ( $n=6$ slices). This LTP was submaximal as the more intense strong TBS protocol resulted in a greater increase in the fEPSP slope $(212.8 \pm 8.6 \% ; n=5)$. When slices were pretreated with $1 \mu \mathrm{M}$ ISO (Gereau et al, 1995) for $10 \mathrm{~min}$ (Figure 2c), weak TBS resulted in a greater increase in fEPSP slope $(213.7 \pm 15.7 \% ; n=5) v s$ control slices that were not treated with ISO. Thus, as reported for other stimulation and slice preparation conditions, $\beta \mathrm{AR}$ activation enhances LTP in the presence of submaximal stimulation (O'Dell et al, 2015).

Next, we tested the hypothesis that activation of group II mGlu receptors would modulate the enhancement of weak TBS LTP by $\beta$ ARs by co-applying the $\mathrm{mGlu}_{2 / 3}$ agonist LY379268 at the minimal concentration we observed in the cAMP experiments to produce maximum potentiation $(100 \mathrm{nM})$ and ISO for $10 \mathrm{~min}$ before LTP induction (Figure 2d). Under these conditions, weak TBS resulted in less potentiation of the fEPSP slope $(147.1 \pm 6.0 \% ; n=5) v s$ ISO alone, suggesting that co-activating $\mathrm{mGlu}_{2 / 3}$ receptors and $\beta$ ARs antagonized the enhancement produced by $\beta$ ARs alone. Because our cAMP experiments implicated a crucial role of $\mathrm{mGlu}_{3}$, we repeated these experiments in the presence of an mGlu ${ }_{3}$ NAM. When slices were pretreated with $30 \mu \mathrm{M}$ VU0469942, a concentration that produced robust inhibition of cAMP accumulation, co-application of LY379268 no longer antagonized the effects of ISO after weak TBS $(195.8 \pm 15.7 \%$; $n=5)$, suggesting that LY379268 is acting through $\mathrm{mGlu}_{3}$ to antagonize the enhancement of LTP by $\beta$ ARs. Figure $2 \mathrm{e}$ summarizes the LTP experiments. Statistical analysis with a one-way ANOVA was significant $\left(\mathrm{F}_{(5,29)}=8.759 ; p<0.001\right)$. Post hoc analysis using the Tukey procedure showed that the strong TBS paradigm produces significantly greater LTP $v s$ the weak TBS $(p<0.05)$. Weak TBS performed in the presence of ISO resulted in significantly greater potentiation than weak TBS alone $(p<0.05)$, and this potentiation by ISO was equivalent to that found in strong TBS experiments $(p>0.05)$. However, the ISO effect was significantly reduced when LY379268 was co-applied to slices $(p<0.05)$. While the $\mathrm{mGlu}_{3} \mathrm{NAM}$ VU0469942 had no effect on weak TBS on its own $(p>0.05)$, LY379268 did not antagonize the enhancement of weak TBS by ISO when applied in the presence of this compound ( $p<0.05 v s$ weak TBS alone).

We also determined whether co-activation of $\mathrm{mGlu}_{3}$ and $\beta$ ARs attenuates the induction of LTP by a strong TBS paradigm (Figure $2 \mathrm{f}$ and $\mathrm{g}$ ). When strong TBS was applied in the presence of ISO, there was no enhancement of LTP $v s$ control experiments $\left(\mathrm{F}_{(2,14)}=2.070, p>0.05 ; n=5\right)$. Furthermore, co-application of ISO and LY379268 did not attenuate the effects of strong TBS in inducing LTP $(p>0.05 ; n=5)$. We also ruled out that our results could be due to altered NMDA receptor signaling caused by the presence of residual ketamine anesthesia used for preparing brain slices. We performed experiments to measure currents in patchclamped neurons in response to focally administered NMDA in brain slice prepared from animals anesthetized with ketamine and control animals that were not (Supplementary Figure S1). We found no difference in currents generated in response to the NMDA puff, suggesting that our results are not due to altered NMDA signaling.

\section{mGlu ${ }_{3}$ Modulation of $\beta$ AR-Induced Enhancement of LTP is Inhibited by the $A_{1}$ Adenosine Receptor Antagonist CPT and FAC}

Previous work demonstrated that co-activation of $\beta$ ARs and group II $m$ Glu receptors in the hippocampus induces release of adenosine and activation of $\mathrm{A}_{1}$ adenosine receptors on presynaptic SC terminals (Gereau and Conn, 1994a). To determine whether $\mathrm{mGlu}_{3}$ activation modulates $\beta \mathrm{AR}$ effects on LTP through this mechanism, we performed a series of experiments in the presence of $200 \mathrm{nM}$ (Schmitt et al, 2012) of the $A_{1}$ adenosine receptor antagonist CPT. Similar to control experiments, there was a differential effect of

\footnotetext{
Figure I Pharmacological and genetic studies indicate that $\mathrm{mGlu}_{3}$ is the group II mGlu subtype that mediates potentiated cyclic-AMP (cAMP) accumulation. Rat hippocampal slice ( $a$ and $b$ ) or mouse cortical slice ( $c-h) c A M P$ assays were performed in the absence (Vehicle) or presence of either $10 \mu M$ isoproterenol

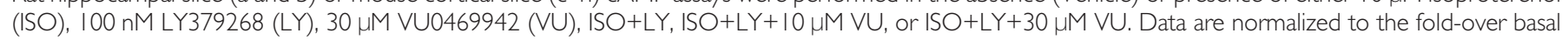
CAMP response and represent the mean of at least three independent experiments performed in at least triplicate with error bars representing SEM. * $p<0.05$ compared with all other conditions except for ISO+LY+ I 0 HM VU. Concentration response curves (CRCs) of LY379268 were performed in rat hippocampal slice (b) or mouse cortical slice (d). cAMP assays in the presence of IO MM ISO and in the absence or presence of I HM (b) or IO HM (d) BINA. For studies utilizing $\mathrm{mGlu}_{2}$ and $\mathrm{mGlu}_{3}$ knockout mice and their wild-type littermates, mouse cortical slice cAMP assays were performed in the absence (Vehicle) or presence of either $10 \mu \mathrm{M}$ ISO, $100 \mathrm{nM}$, or I $\mu$ M LY379268 (LY) as indicated, and ISO+LY, or ISO+LY+I $\mu M$ MNI- I 37 (MNI). (e and f) Represent data that were obtained from experiments in WT littermates and data from $\mathrm{mGlu}_{2}$ and $\mathrm{mGlu} 3 \mathrm{KO}$ mice are presented in $\mathrm{g}$ and h, respectively. Data are normalized to the fold-over basal CAMP response and represent the mean of four independent experiments performed blinded to the genotype in quadruplicate with error bars representing SEM. *p $<0.05$ compared with all other conditions except for either ISO+LY (I00 nM) or ISO+LY (I HM) where applicable.
} 
a

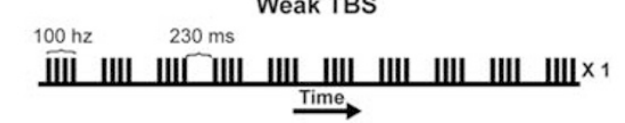

b
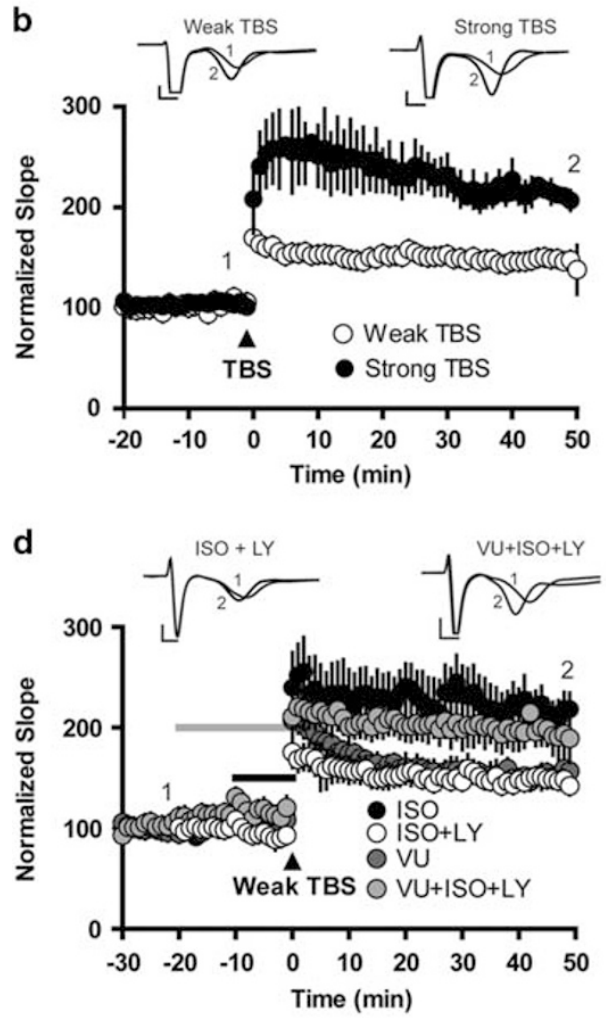

f

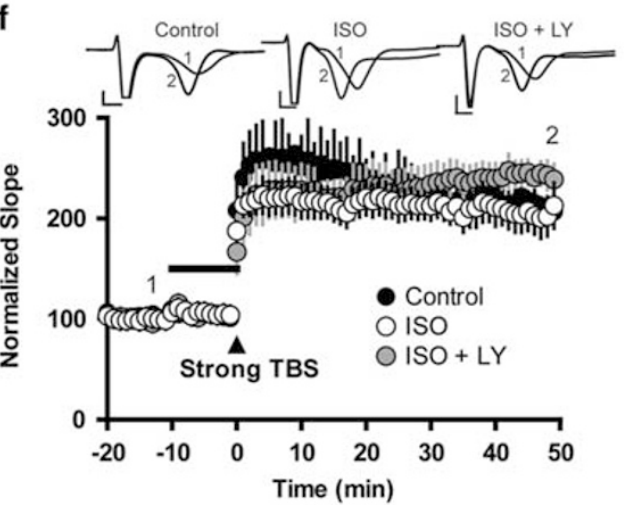

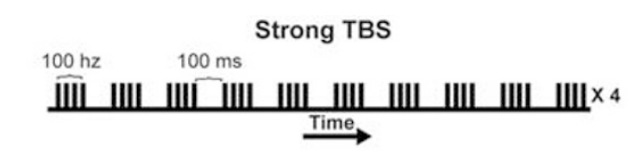

C

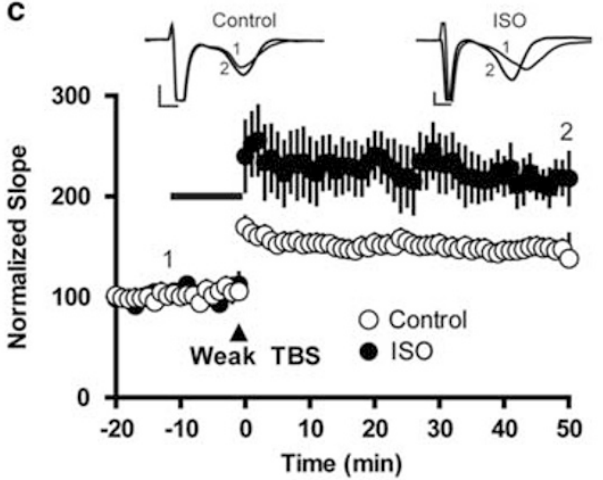

e

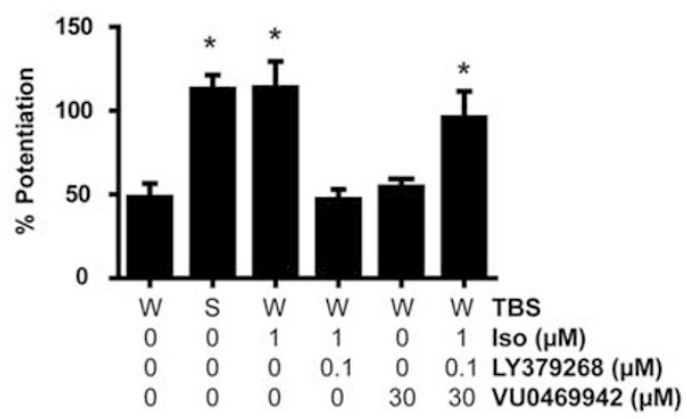

g

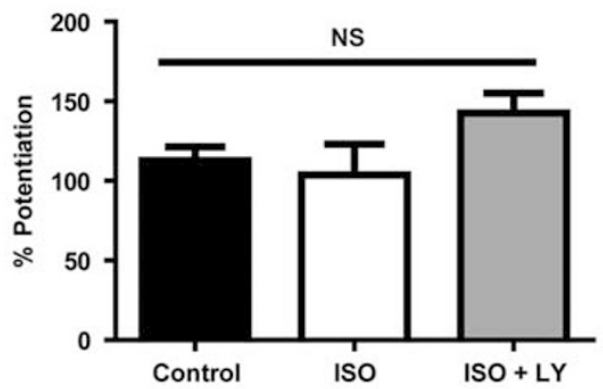

Figure 2 mGlu 3 activation blocks the long-term potentiation (LTP) enhancing effects of $\beta A R s$. (a) Schematic of weak and strong theta burst stimulation (TBS) protocols. (b) Average time course of normalized field excitatory postsynaptic potential (fEPSP) slopes recorded from the SC-CAI synapse in rat hippocampal slices. Strong TBS induced a larger potentiation of fEPSPs compared with weak TBS measured 50 min post stimulation. (c) Bath application of ISO (I MM) enhances the effects of weak TBS. Black horizontal bar represents drug add. (d) When ISO and LY379268 (I00 nM) are co-applied, the enhancing effects of ISO were antagonized relative to ISO-alone experiments. This blockade was reversed when slices were pretreated with the mGlu $\mathrm{NAM}_{3}$ VU0469942 (30 HM). The gray horizontal bar represents the NAM drug addition and the black horizontal bar represents ISO \pm LY379268. (e) Summary data for experiments in (b-d). Bars represent mean \pm SEM. * $p<0.05$ vs control, I $\mu M$ ISO + LY379268, and $30 \mu M$ VU0469942. (f and g) ISO does not enhance and ISO+LY379268 does not attenuate the effects of strong TBS. Insets for $b-d$ and $f$ are representative fEPSP traces for the various experimental conditions measured during baseline (I) and 50 min post stimulation (2). Calibration: I mV vertical and I ms horizontal for all traces.

stimulation intensity on fEPSP slope with strong TBS $(n=4)$ producing significantly greater potentiation than weak TBS $(n=3$; Figure $3 \mathrm{a}$ and $\mathrm{b}$; two-way ANOVA main effect of stimulation $\left.\mathrm{F}_{(1,11)}=14.3 ; p<0.05\right)$. ISO also was able to significantly enhance the effects of weak TBS in the presence of CPT (Figure $3 \mathrm{c}$ and $\mathrm{d} ; 166.1+8.8 \%$ vs $127.1 \pm 12.3 \%$;
$\mathrm{F}_{(2,15)}=6.505, p<0.05$; Tukey post-test $v s$ no drug $p<0.05$; $n=5)$. However, activation of $\mathrm{mGlu}_{3}$ with LY379268 $(n=4)$ no longer antagonized the enhancement of weak TBS by ISO in presence of CPT and also resulted in a significant LTP enhancement $v s$ control slices $(181.1 \pm 8.1 \%$ baseline slope; $p<0.05$ vs no drug). It should be noted that CPT appears to 
blunt the potentiating effects of ISO on weak TBS $v s$ experiments performed in the absence of CPT (compare Figure $2 \mathrm{e}$ and Figure $3 \mathrm{~d}$ ). In fact, it appears that both the levels of LTP in the control (no drug) and ISO conditions are equivalently reduced. However, there is still a clear differentiation between the control (no drug) and ISO
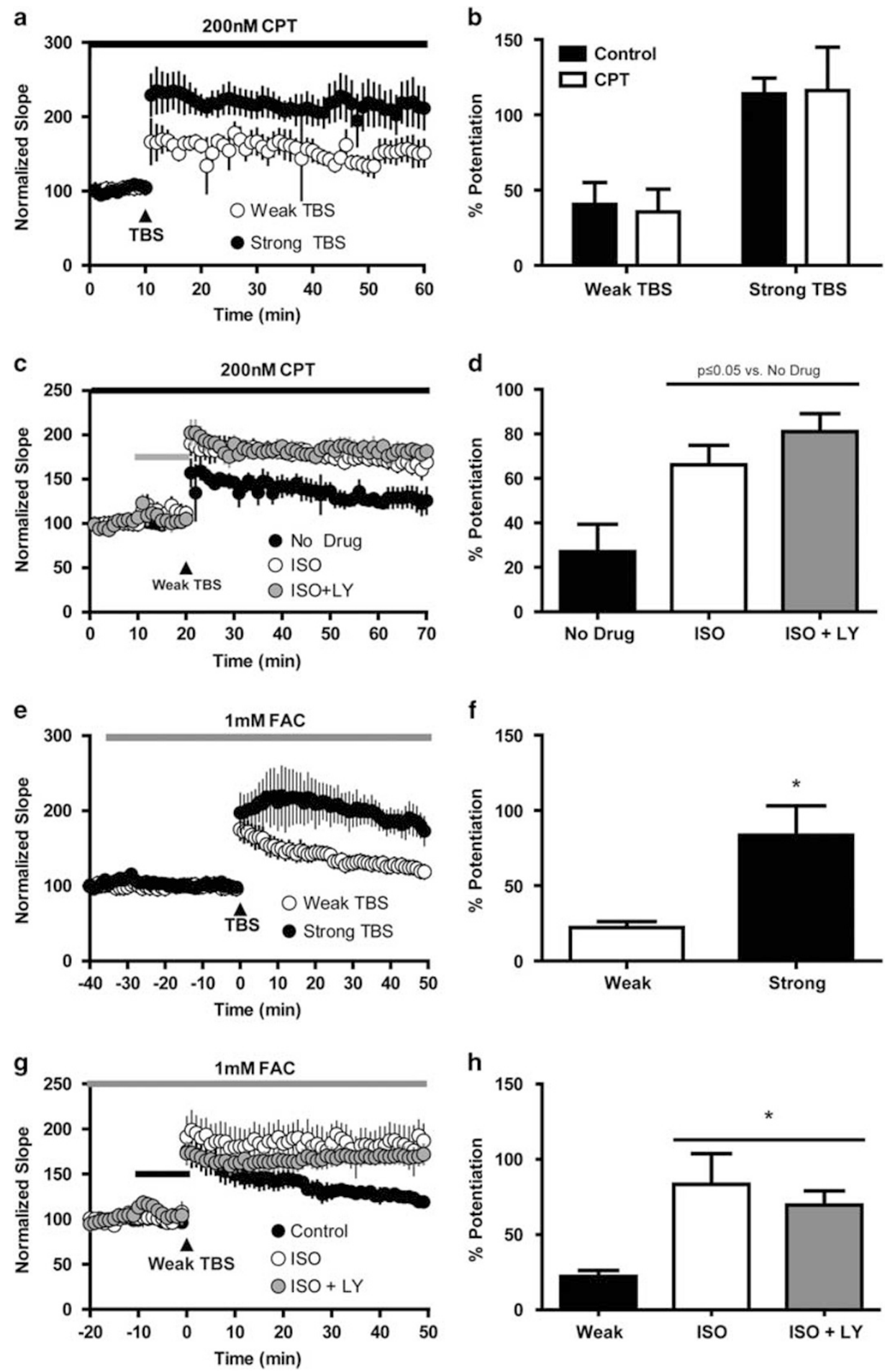

Figure $3 \mathrm{CPT}$, an $\mathrm{A}_{1}$ adenosine antagonist, and fluoroacetic acid (FAC) occlude mGlu -mediated blockade of $\beta$ AR-enhanced LTP. (a) Differential potentiating effects of weak and strong TBS in the presence of the $A_{1}$ adenosine receptor antagonist CPT (200 nM). (b) Quantification of the effects of weak and strong TBS from a. Weak and strong TBS results in similar levels of LTP when compared with control experiments presented in Figure 3. (c and d) Relative to control, ISO (I MM) applied in the presence of CPT enhances the effects of weak TBS, but ISO+LY379268 (I00 nM) no longer attenuates this enhancement. (e) Time course of normalized fEPSP slopes recorded in the presence of the glial-specific toxin FAC before and after TBS stimulation. Weak and strong TBS produce differential levels of LTP measured 50 min post stimulation in the presence of FAC. ( $f$ ) Quantification of data presented in e represented as the mean \pm SEM. (g) Relative to control experiments, ISO (I HM) and ISO+LY379268 (I00 nM) enhance the effects of weak TBS. (h) Quantification of data presented in $g$ represented as the mean \pm SEM $* p<0.05$ compared with weak TBS alone. 
conditions; thus, we are confident that there would still be a signal window to observe antagonizing effects of LY379268. Apart from the presence of CPT, the conditions for these experiments were identical and were performed in parallel, often on the same day in slices from the same animals. It is possible that this blunting effect is due to off-target effects of CPT, such as activity toward phosphodiesterases. Despite this caveat, results of these experiments indicate that modulation of LTP by $\mathrm{mGlu}_{3}$ requires activation of $A_{1}$ adenosine receptors.

Results from anatomical studies indicate that $\mathrm{mGlu}_{3}$ is primarily localized on glial cells and not neurons in area CA1 of the hippocampus (Ohishi et al, 1993). In addition, previous work suggests that the large increases in cAMP accumulation and adenosine release induced by co-activation of group II mGlu receptors and $\beta$ ARs are mediated by actions on receptors on astrocytes and can be blocked by selective astrocytic metabolic toxins (Winder et al, 1996). Thus, we hypothesized that $\mathrm{mGlu}_{3}$ modulation of enhancement of LTP by $\beta$ AR activation is also dependent upon an astrocytic mechanism. To test this hypothesis, we utilized the metabolic toxin FAC that selectively inhibits astrocyte function. FAC (1 mM; Zhang et al, 2003) was bath-applied after a 5-min drug-free baseline period (Figure $3 \mathrm{e}$ ). Consistent with our initial LTP experiments, strong TBS $(n=3)$ resulted in significantly greater potentiation of the fEPSP slope $v s$ the weak TBS $\left(n=5\right.$; Figure $3 \mathrm{e}$ and $\mathrm{f} \mathrm{F}_{(2,13)}=7.573$; $p<0.05$; Tukey post hoc test $p<0.05$ ). Furthermore, in the presence of FAC, ISO was able to enhance the effects of weak TBS (Figure $3 g$ and $h$ ), resulting in greater LTP $v s$ control slices $(p<0.05 ; n=4)$. Slices co-treated with ISO and LY379268 also resulted in enhanced weak TBS-induced LTP $v s$ control $(p<0.05 ; n=5)$, but there was no significant difference in TBS-induced LTP vs ISO alone experiments $(p>0.05)$. Taken together, these data suggest that $\beta \mathrm{AR}$ activation enhances weak TBS-induced LTP through a neuronal mechanism, but the effect of $\mathrm{mGlu}_{3}$ activation on $\beta$ AR-mediated potentiation of LTP may require astrocytic signaling.

\section{$\mathrm{mGlu}_{3}$ and $\beta \mathrm{AR}$ are Co-Expressed in Hippocampal Astrocytes}

Our biochemical and electrophysiological studies indicate that $\mathrm{mGlu}_{3}$ and $\beta$ ARs act in astrocytes to modulate synaptic plasticity. This mechanism would require $\mathrm{mGlu}_{3}$ and $\beta \mathrm{ARs}$ to be expressed together in individual astrocytes within the hippocampus. Although there is evidence in the literature that $\mathrm{mGlu}_{3}$ (Bradley and Challiss, 2012) and $\beta$ AR (Laureys et al, 2010) are expressed in astrocytes, to our knowledge coexpression of these receptors in hippocampal astrocytes has not been evaluated. Thus, we first performed colocalization experiments where we labeled for the astrocyte-specific protein GFAP, $\beta 2 \mathrm{AR}$, and $\mathrm{mGlu}_{3}$. As shown in Figure 4, $\times 100$ images reveal a neuropil-like distribution of both $\beta 2 \mathrm{AR}$ and $\mathrm{mGlu}_{3}$ and that a portion of the immunoreactivity for these receptors is colocalized with GFAP. While the neuropil staining for both $\mathrm{mGlu}_{3}$ and $\beta 2 \mathrm{AR}$ likely includes substantial neuronal staining, colocalization of these receptors in GFAP-immunopositive elements is consistent with astrocytic expression. High-magnification examination $(\times 200$ images, $\times 100$ optics with $\times 2$ digital zoom) indicates that $\mathrm{mGlu}_{3}$ and $\beta 2 \mathrm{AR}$ appear to be expressed within the same astrocyte. Areas with clusters of vesicle-like structures that co-label for $\beta 2 \mathrm{ARs}$ and $\mathrm{mGlu}_{3}$ within GFAP+ structures are indicated by arrowheads. Importantly, the $\mathrm{mGlu}_{3}$ antibody appears to be specific as staining was absent in the presence of an $\mathrm{mGlu}_{3}$-blocking peptide.

Because of the dense neuropil-like staining of $\beta 2 \mathrm{ARs}$ and $\mathrm{mGlu}_{3}$ throughout the hippocampus, we sought to increase confidence in coexpression of $\beta 2 \mathrm{ARs}$ and $\mathrm{mGlu}_{3}$ in astrocytes through the use of RNAscope-based staining methods. In order to determine whether $\beta 2 \mathrm{AR}$ and $\mathrm{mGlu}_{3}$ RNA were coexpressed in the same astrocytes, we developed a hybrid method that used traditional immunohistochemical (IHC) to label GFAP+ astrocytes with RNAscope technology to label $\beta 2 \mathrm{AR}$ and $\mathrm{mGlu}_{3}$. Again, both $\beta 2 \mathrm{AR}$ and $\mathrm{mGlu}_{3}$ were found throughout the hippocampus. However, $\times 200$ images that allow for the inspection of single astrocytes clearly revealed that both $\beta 2 \mathrm{AR}$ (arrows) and $\mathrm{mGlu}_{3}$ (filled-in arrows) RNAs could be found within the same GFAP+ structures. Again, negative controls (probes for nonmammalian genes) were nearly completely blank. Taken together, our traditional IHC and RNAscope provide strong evidence that both $\beta 2 \mathrm{AR}$ and $\mathrm{mGlu}_{3}$ are found within the same astrocyte, giving anatomical verification that our proposed mechanism is possible.

\section{Blockade of $\beta \mathrm{AR}$ and Activation of $\mathrm{mGlu}_{3}$ Have Similar Effects on Contextual Fear Conditioning}

When taken together with previous studies of $\mathrm{mGlu}_{3}$ and $\beta$ AR signaling, our biochemical and electrophysiological studies suggest that astrocytic $\mathrm{mGlu}_{3}$ and $\beta$ ARs cooperate to produce unique signaling that results in functional antagonism of the ability of neuronal $\beta$ ARs to enhance LTP in the hippocampus. Therefore, we reasoned that activation of $\mathrm{mGlu}_{3}$ could inhibit forms of hippocampal-dependent learning that are dependent on $\beta \mathrm{AR}$ activation in a manner similar to $\beta \mathrm{AR}$ antagonists. To test this hypothesis, we trained rats in a contextual fear memory reconsolidation task (Figure 5a). As previously reported (Taherian et al, 2014), propranolol-treated animals exhibited significantly less freezing (Figure 5b; 29.6 $\pm 4.6 \%$ ) vs vehicle-treated rats $\left(56.1 \pm 8.3 \% ; \mathrm{F}_{(5,73)}=3347, p<0.05\right.$, Dunnett's post-test $v s$ vehicle $p<0.05)$, indicative of a disruption of memory reconsolidation. Furthermore, the $\mathrm{mGlu}_{2 / 3}$ agonist LY379268 dose-dependently decreased freezing to context, reaching significance at a dose of $3 \mathrm{mg} / \mathrm{kg}(19.8 \pm 6.1 \%$; $p<0.05 v s$ vehicle). When LY379268 was co-administered with the $\mathrm{mGlu}_{3}$ NAM, VU0650786, there was no longer a significant reduction in freezing vs vehicle-treated rats $(36.1 \pm 5.0 \%$; $p>0.05)$. While the $\mathrm{mGlu}_{3} \mathrm{NAM}$ did not fully reverse the LY379268 effect, this partial reversal is consistent with our hypothesis that activation of $\mathrm{mGlu}_{3}$ can disrupt contextual fear memory reconsolidation. In addition to having an important role in reconsolidation of fear memory, previous studies also suggest that $\beta$ ARs have an important role in consolidation of some forms of fear memory and that propranolol disrupts fear memory consolidation (Gao et al, 2016). Thus, we also determined the effect of the group II mGlu receptor agonist on contextual fear memory consolidation (Supplementary Figure S2). Rats treated with propranolol $(10 \mathrm{mg} / \mathrm{kg})$ or LY3792628 (3 mg/kg) after fear 

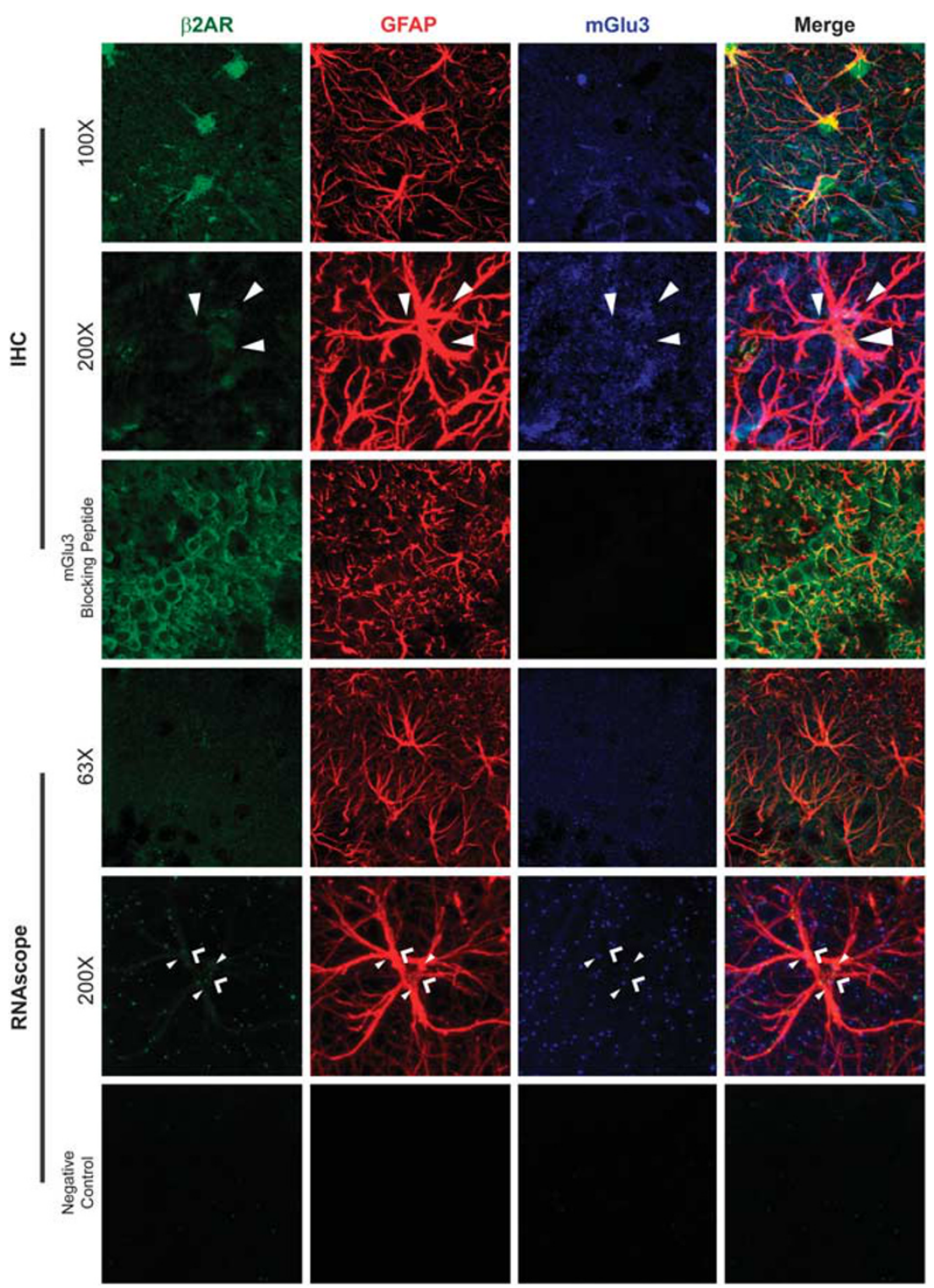

Figure $4 \mathrm{mGlu}_{3}$ and $\beta 2$ adrenergic receptors ( $\beta 2 \mathrm{ARs}$ ) can co-localize to astrocytes. For immunohistochemical $(\mathrm{IHC})$ analysis, $\times 100$ images indicate several instances of $\beta 2 A R s$ (green) and GGlu $_{3}$ (blue) within the cell bodies and processes of astrocytes demonstrated by GFAP staining (red). Additional $\beta 2 A R$ and $\mathrm{mGlu}_{3}$ staining appears in a neuropil-like pattern, implicating expression in diverse cell types. $\times 200$ images $(\times 100$ objective with a $\times 2$ digital zoom) implicate that $\beta 2 \mathrm{ARs}$ (green) and $\mathrm{mGlu}_{3}$ (blue) can be found in vesicular-like structures throughout astrocytes (red), which are marked by filled-in arrowheads. Inclusion of an $\mathrm{mGlu}_{3}$ antibody-blocking peptide within the staining reaction abolishes the visualization of $m G u_{3}$. RNAscope analysis of $\beta 2 A R$ and $m G l u_{3}$ also reveals expression throughout the hippocampus. High-magnification $\times 200$ images reveal that $\beta 2 A R$ (arrowheads) and mGlu (filled arrowheads) can be found within GFAP+ structures. Negative control probes yield nearly completely clean images. Images are representative of sections taken from at least three animals.

conditioning exhibited significantly less contextual freezing $24 \mathrm{~h}$ later $(49.6 \pm 5.3 \%$ and $42.9 \pm 6.0 \%$, respectively, $v s$ vehicle-treated animals $\left(69.8 \pm 5.1 \% ; \quad \mathrm{F}_{(5,71)}=3.3 .893\right.$, $p<0.05$, Dunnett's post-test $v s$ vehicle $p<0.05)$. When the LY379268 $(3 \mathrm{mg} / \mathrm{kg})$ was co-administered with the $\mathrm{mGlu}_{3}$ NAM VU0650786 $(56.6 \mathrm{mg} / \mathrm{kg})$, there was no longer a significant reduction in freezing $v s$ vehicle-treated rats $(64.5 \pm 5.4 \% ; p>0.05)$.

In our electrophysiology experiments, the LTPantagonizing effects of $\mathrm{mGlu}_{3}$ activation were dependent upon $A_{1}$ adenosine receptor signaling. We next performed a series of experiments to test the hypothesis that disruption of contextual fear memory reconsolidation by $\mathrm{mGlu}_{3}$ is similarly dependent upon $A_{1}$ receptors. First, we tested the hypothesis that $A_{1}$ receptor activation could disrupt reconsolidation. Similar to the effects we observed with propranolol and LY379268, the selective $A_{1}$ agonist CCPA dose-dependently $(0.1-0.15 \mathrm{mg} / \mathrm{kg})$ decreased freezing during the context test (Figure $5 \mathrm{c}$ ) reaching significance at the highest dose tested $\left(26.8 \pm 5.8 \% ; \mathrm{F}_{(2,31)}=3.351, p<0.05\right.$; Dunnett's post-test $p<0.05 v s$ vehicle). To test the hypothesis that the behavioral effects of $\mathrm{mGlu}_{3}$ activation by LY379268 were dependent upon $A_{1}$ receptors, we used the selective antagonist PQ69. When administered alone, we found no 
a
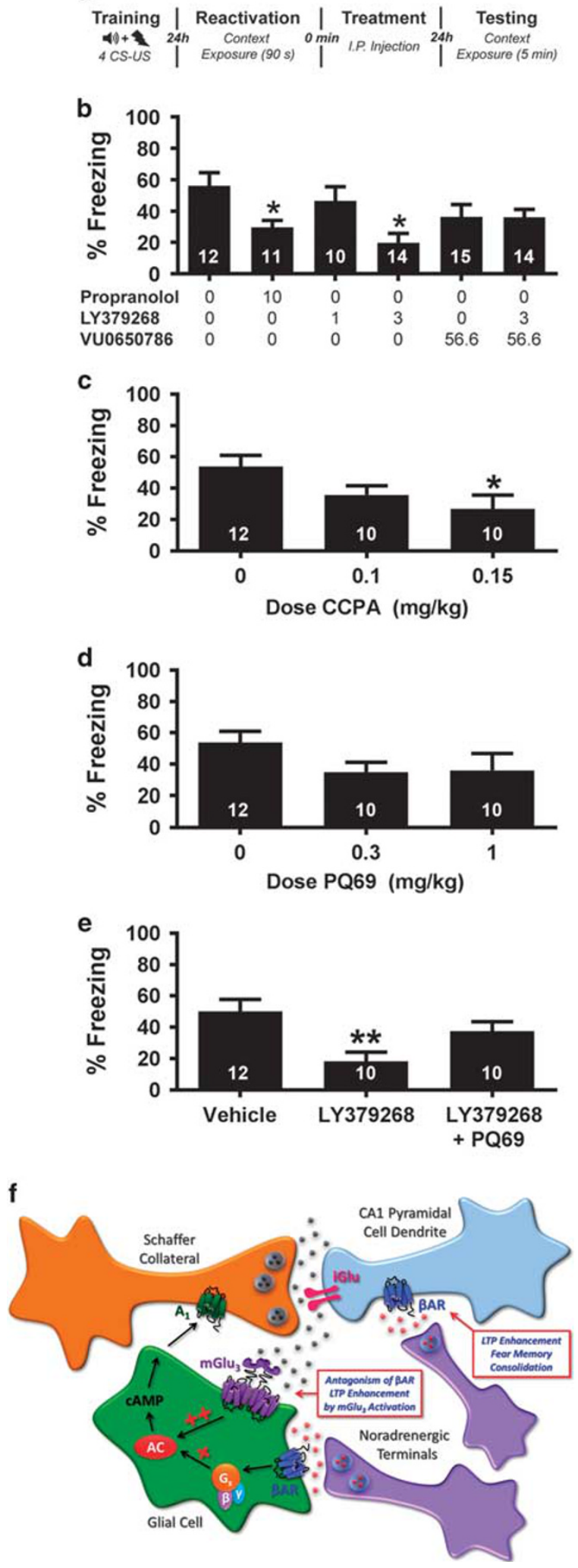

effect of PQ69 $(0.3-1 \mathrm{mg} / \mathrm{kg})$ on freezing during the context test (Figure 5d; $\left.F_{(2,31)}=1.720 p>0.05\right)$. However, when co-administered with LY37268 (3 mg/kg), PQ69 (1 mg/kg) blocked the disruption effects of LY37268 in reducing
Figure 5 Activation of $\mathrm{mGlu}_{3}$ disrupts reconsolidation of contextual fear memory. (a) Schematic of the behavioral testing protocol. (b) Propranolol and LY379268 disrupt reconsolidation of contextual fear memory as demonstrated by decreased freezing during 5 min context exposure. The mGlu 3 NAM VU0650786 reverses the disruption induced by LY379268. (c) The $A_{1}$ receptor agonist CCPA dose-dependently disrupts reconsolidation. ( $d$ and e) The A, antagonist PQ69 had no effect alone, but blocks the disruption induced by LY379268. (f) A model for mGlu 3 -mediated glialneuronal communication at the SC-CAI hippocampal synapse. When glial $\mathrm{mGlu}_{3}$ is coincidently activated with $\beta$-adrenergic receptors ( $\left.\beta A R s\right)$, the $\beta A R-m e d i a t e d$ production of CAMP by stimulation of adenylate cyclase (AC) is greatly potentiated. CAMP metabolites then activate $A_{\text {I }}$ adenosine receptors presynaptically expressed on the Schaffer Collateral (SC) terminals, resulting in a depression of neurotransmission at the SC-CAI synapse in the hippocampus. This glial-neuronal signaling also results in antagonism of $\beta A R$ agonist-mediated potentiation of weak TBS-induced LTP. Quantification of contextual fear memory on testing day presented as mean \pm SEM of the percentage of time freezing during the 5 -min context exposure. Inset numbers in bars indicate the number of animals in each condition. ${ }^{*} p \leqslant 0.05$ and $* * p<0.01$ relative to vehicle-treated animals.

freezing behavior $v s$ vehicle (Figure $5 \mathrm{e} ; \mathrm{F}_{(2,35)}=6.024$, $p<0.05$; Dunnett's post-test $v s$ vehicle $p>0.05)$. Taken together, this is consistent with the hypothesis that $\mathrm{mGlu}_{3}$ is acting through $A_{1}$ receptors in order to disrupt contextual fear memory reconsolidation.

\section{DISCUSSION}

The present work has identified a role of $\mathrm{mGlu}_{3}$ in hippocampal synaptic plasticity and modulation of fear memory. As previously reported, we found that activation of group II mGlu receptors potentiates cAMP formation induced by agonists of the $\mathrm{G}_{\mathrm{s}}$-coupled $\beta \mathrm{AR}$ (Moldrich et al, 2002; Winder and Conn, 1993, 1995; Winder et al, 1996). Our results suggest that this effect is mediated by $\mathrm{mGlu}_{3}$ as we found that cAMP potentiation is antagonized by the selective $\mathrm{mGlu}_{3}$ NAM VU0469942 and cannot be potentiated by the mGlu 2 PAM BINA. Furthermore, this effect occurs in $\mathrm{mGlu}_{2}$ but not in $\mathrm{mGlu}_{3} \mathrm{KO}$ mice. Although it is counterintuitive for a $\mathrm{G}_{\mathrm{i} / \mathrm{o}}$-coupled GPCR to stimulate the production of cAMP, the effects of $\mathrm{G}_{\mathrm{i} / \mathrm{o}}$-coupled GPCR activation on adenylate cyclase (AC) are dependent on the form of AC that is expressed in a particular cell type. AC type II is activated by the $\beta \gamma$ subunits associated with $\mathrm{G}_{\mathrm{i} / \mathrm{o}}$, allowing a $\mathrm{G}_{\mathrm{i} / \mathrm{o}}$-mediated potentiation of a $\mathrm{G}_{\mathrm{s}}$-coupled GPCR's (such as $\beta$ ARs) activation of AC (Tang and Gilman, 1991). Type II AC (but not Type IV) has been shown to be enriched by transcriptome analysis in astroglia (Cahoy et al, 2008; Orre et al, 2014). In addition, an RNASeq transcriptome and splicing database of glia, neurons, and vascular cells (Zhang et al, 2014) in the cerebral cortex showed that type II AC is present in astrocytes, whereas Type IV AC is not present.

To evaluate the electrophysiological consequences of $\mathrm{mGlu}_{3}-\beta \mathrm{AR}$ synergistic signaling, we evaluated LTP at the SC-CA1 synapse in rat hippocampal slices. At this synapse, activation of $\beta$ ARs can enhance excitatory synaptic transmission and synaptic plasticity (Chavez-Noriega and Stevens, 1994; Gereau and Conn, 1994b) and can facilitate the induction of LTP when low-frequency stimulation paradigms are performed in the presence of a $\beta \mathrm{AR}$ agonist 
(O'Dell et al, 2015). We found that the $\beta$ AR agonist ISO enhances induction of LTP by a weak TBS protocol. When $\beta$ ARs and $\mathrm{mGlu}_{2 / 3}$ were co-activated with ISO and LY379268, the coincident activation of group II mGlu receptors reversed the ISO-induced enhancement of LTP. Our data suggest that the ability of the group II mGlu receptor agonist to reverse ISO effects on LTP is completely blocked by the $\mathrm{mGlu}_{3}$-selective NAM VU0469942, suggesting that this effect is mediated by $\mathrm{mGlu}_{3}$. In addition, the effect of the group II mGlu receptor agonists requires $\mathrm{A}_{1}$ adenosine receptors and functional astrocytes as LY379268 no longer antagonized the effects of ISO in the presence of the $A_{1}$ antagonist CPT or the glial toxin FAC. Moreover, the results of our anatomical studies showed that $\beta$ ARs and $\mathrm{mGlu}_{3}$ colocalize in hippocampal astrocytes. Overall, this is consistent with previous reports that co-activating group II mGlu receptors and $\beta$ ARs on hippocampal astrocytes leads to release of adenosine, which can then modulate synaptic transmission at neighboring SC synapses (Gereau and Conn, 1994b; Winder et al, 1996). Previous studies have shown that group II mGlus cooperates with other Gs-coupled receptors to potentiate cAMP in a similar manner, including $\mathrm{A}_{2}$ adenosine receptors (Winder and Conn, 1993). It is therefore conceivable that astrocyte-derived adenosine may have a dual function by acting on astrocytic $A_{2}$ receptors to perpetuate cAMP accumulation and neuronal $A_{1}$ receptors to suppress synaptic transmission.

Multiple studies suggest that the ability of $\beta \mathrm{AR}$ activation to enhance LTP is likely to have an important role in facilitating memory processes (Murchison et al, 2004; O'Dell et al, 2015), and that this can be important for memory formation in novel environments. However, it is also conceivable that during periods of intense stress when noradrenergic activity is high, this mechanism may contribute to formation of pathological memories, as would be the case in post-traumatic stress disorder (PTSD). Recent work indicates that memories undergo a reconsolidation process after retrieval, during which they are labile and susceptible to manipulation (Otis et al, 2015). $\beta$ ARs have a critical role in this process and the antagonist propranolol can disrupt reconsolidation of fearful memories in both rodents and humans (Otis et al, 2015; Taherian et al, 2014). In fact, pharmacological disruption of memory reconsolidation may serve a therapeutic approach for PTSD (Otis et al, 2015). In the present study, we found that the $\mathrm{mGlu}_{2 / 3}$ agonist LY379268 disrupted contextual fear memory reconsolidation in rats in a manner similar to propranolol. This disruption was reversed by the selective $\mathrm{mGlu}_{3}$ NAM VU0650786, suggesting a critical role of this receptor in this effect. The fact that VU0650786 did not produce a full reversal is likely because of the fact that the potency of the NAM is relatively weak compared with that of LY379268 as an agonist. Alternatively, this could indicate that $\mathrm{mGlu}_{2}$ may also contribute to this response and should be explored in future studies. Consistent with our electrophysiology studies, the effects of LY379268 were dependent upon $A_{1}$ receptors as LY379268 no longer disrupted reconsolidation in the presence the $\mathrm{A}_{1}$ antagonist PQ69. Also of note, animals that received VU0650786 alone appeared to have reduced freezing relative to controls. While this effect was not statistically significant, one hypothesis for this reduction is that $\mathrm{mGlu}_{3}$ activation is required for the reconsolidation process. However, it would be expected that activation of mGlu $_{3}$ by LY379268 would enhance reconsolidation and freezing during the context or at the very least result in equivalent freezing relative to controls. Because LY379268 caused a clear reduction in freezing, this does not appear to be the case.

We also observed that propranolol and LY379268 also disrupt fear memory consolidation, and the effects of LY379268 were blocked by the mGlu 3 NAM VU0650786. This is especially interesting in light of a recent study demonstrating that astrocytic $\beta$ ARs modulate consolidation of fear memory using the inhibitory avoidance task (Gao et al, 2016). Taken together with the current study, these results suggest that the effects of activation of astrocytic $\beta$ ARs on hippocampal-dependent memory consolidation are likely to be dependent on the physiological state and can be reduced by coincident activation of astrocytic $\mathrm{mGlu}_{3}$. In future studies it will be important to determine the behavioral or physiological context in which these receptors are co-activated. It will also be important to determine the role astrocytes have in $\mathrm{mGlu}_{3}$-induced disruption of memory reconsolidation. Unfortunately, very few tools exist to selectively manipulate astrocytic receptors in vivo. Because the progenitor cells for many neuronal populations are radial glia, including cortical and hippocampal pyramidal cells (Casper and McCarthy, 2006), genetic manipulations of receptors selectively in astrocytes are difficult (Casper et al, 2007). Even using inducible strategies may not result in astrocyte-specific effects, as recently demonstrated for the dnSNARE mouse (Fujita et al, 2014). Overall, combined with our recent report that activation of $\mathrm{mGlu}_{3}$ is required for fear extinction learning (Walker et al, 2015), the results of our behavioral experiments indicate that potentiators of this receptor may be a promising therapeutic strategy for the treatment of PTSD.

Coincident activation of $\mathrm{mGlu}_{3}$ and $\beta$ ARs could also serve as a protective feedback mechanism to prevent excitotoxic injury during instances of prolonged stress. The activation of group II mGlu receptors has long been known to have neuroprotective activity both in vitro (Battaglia et al, 1998; Bruno et al, 1995; Bruno et al, 1994) and in vivo (Kingston et al, 1999a; Kingston et al, 1999b). Previous studies have shown that $\mathrm{mGlu}_{2 / 3}$ agonist-induced neuroprotection in mixed cultures of cortical neurons and astrocytes occurs via a glial-neuronal mechanism requiring astrocytic $\mathrm{mGlu}_{3}$, and that neuronal $\mathrm{mGlu}_{2}$ activation may actually be harmful to neurons exposed to toxic insults (Corti et al, 2007). Importantly, the neuroprotective effects of group II mGlu receptor activation absolutely require $\mathrm{mGlu}_{3}$ as they are absent when mixed cultures of cortical neurons and astrocytes contain astrocytes prepared from $\mathrm{mGlu}_{3} \mathrm{KO}$ mice (Caraci et al, 2011; Corti et al, 2007).

The astrocytic activation of $\mathrm{mGlu}_{3}$ leads to a number of neuroprotective signaling cascades including the stimulation of the mitogen-activated protein kinase and phosphoinositide 3-kinase pathways (Ciccarelli et al, 2007; Corti et al, 2007). The activation of these pathways then leads to the increased production and release of transforming growth factor- $\beta$ (TGF- $\beta$ ) from glia (Bruno et al, 1998), which in turn acts to protect neurons against excitotoxicity (Bruno et al, 1998; Bruno et al, 1997). In addition, these studies have also been recently extended to show a role for glial $\mathrm{mGlu}_{3}$ 
activation in mediating neuroprotection from $\beta$-amyloid $(\mathrm{A} \beta)$ toxicity through a TGF- $\beta$ mechanism (Caraci et al, 2011), suggesting that $\mathrm{mGlu}_{3}$ activation may be a viable therapeutic approach for the treatment of Alzheimer's disease. Activation of $\mathrm{mGlu}_{3}$ in astrocytes also leads to the release of a number of other important factors for neuronal survival, including nerve growth factor, S-100 $\beta$ protein (Ciccarelli et al, 1999), brain-derived neurotrophic factor (Di Liberto et al, 2010), and glial-derived neurotrophic factor (Battaglia et al, 2009), providing additional non-TGF- $\beta$ mechanisms for $\mathrm{mGlu}_{3}$-mediated neuroprotection. The role of $\mathrm{mGlu}_{3}$ in the form of glial-neuronal communication outlined here may provide another distinct mechanism of neuroprotection driven by astroglial $\mathrm{mGlu}_{3}$. Thus, the current studies also support the development of $\mathrm{mGlu}_{3}$ activators as a novel therapeutic approach for neuroprotection.

In conclusion, the results of the present studies provide a conceptual framework in which $\mathrm{mGlu}_{3}$ and $\beta$ ARs interact to influence cAMP signaling, synaptic plasticity, and potential behavior (Figure 5f). Noradrenergic afferents can modulate cellular excitability and potentiate LTP through neuronal $\beta$ ARs. Co-activation of $\mathrm{mGlu}_{3}$ and $\beta$ ARs located on astrocytes will produce large cAMP accumulation in these cells and release of cAMP metabolites into the perisynaptic space. These metabolites then activate presynaptic $A_{1}$ adenosine receptors to antagonize the LTP-enhancing effects of $\beta \mathrm{AR}$ agonists. Systemically administered agonists or potentiators of $\mathrm{mGlu}_{3}$ could interact with endogenous NA through this mechanism to modulate behavior such as fear memory reconsolidation and afford neuroprotection against cellular damage from excess glutamatergic activity. However, this could also result in the formation of pathological associations, as is observed in cases of PTSD. Consistent with this, there are reports that compounds that act as $\beta \mathrm{AR}$ antagonists are efficacious in both preclinical models of PTSD as well in the clinic (Otis et al, 2015).

\section{FUNDING AND DISCLOSURE}

This work was supported by a National Institute of Neurological Disorders and Stroke (NINDS) grant R01NS031373 (to PJC). DJS was a recipient of a National Alliance for Research on Schizophrenia and Depression (NARSAD), Dylan Tauber Young Investigator Award. AGW was supported by a postdoctoral fellowship through the PhRMA Foundation. Immunohistochemical experiments were performed in part through the use of the Vanderbilt Cell Imagining Shared Resource (supported by NIH grants CA68485, DK20593, DK58404, DK59637, and EY08126). Drs Emmitte, Lindsley, and Conn are inventors on patents protecting different classes of $\mathrm{mGlu}_{2}$ and $\mathrm{mGlu}_{3}$ modulators. Dr Emmitte's work has been funded by the NIH. Dr Lindsley's work has been funded by the NIH, Bristol-Myers Squibb, AstraZeneca, Michael J Fox Foundation, as well as Seaside Therapeutics. He has consulted for AbbVie and received compensation. Dr Conn has been funded by NIH, Johnson \& Johnson, AstraZeneca, Bristol-Myers Squibb, Michael J Fox Foundation, and Seaside Therapeutics. Over the past 3 years, he has served on the Scientific Advisory Boards of Seaside Therapeutics, Michael J Fox Foundation,
Stanley Center for Psychiatric Research Broad Institute (MIT/Harvard), Karuna Pharmaceuticals, Lieber Institute for Brain Development Johns Hopkins University, Clinical Mechanism (POCM) and Proof of Concept (POC) Consortium, and Neurobiology Foundation for Schizophrenia and Bipolar Disorder. The authors declare no conflicts of interest.

\section{ACKNOWLEDGMENTS}

We thank Danny G Winder for his insight and thoughtful comments and Meredith J Noetzel for blinding the studies performed with $\mathrm{mGlu}_{2}$ and $\mathrm{mGlu}_{3} \mathrm{KO}$ mice. Authors DJS, AGW, ASL, JWD, DJF, RKS, ZX, JMR, MSM, BJS, XL, KAE, CWL, and PJC participated in research design; DJS, AGW, ASL, JWD, DJF, RKS, ZX, XL, MSM, BJS, and JMR conducted experiments; DJS, AGW, ASL, DJF, RKS, MSM, BJS, and ZX performed data analysis; and DJS, AGW, and PJC wrote or contributed to the writing of the manuscript.

\section{REFERENCES}

Battaglia G, Bruno V, Ngomba RT, Di Grezia R, Copani A, Nicoletti F (1998). Selective activation of group-II metabotropic glutamate receptors is protective against excitotoxic neuronal death. Eur J Pharmacol 356: 271-274.

Battaglia G, Molinaro G, Riozzi B, Storto M, Busceti CL, Spinsanti P et al (2009). Activation of mGlu3 receptors stimulates the production of GDNF in striatal neurons. PLoS ONE 4: e6591.

Bradley SJ, Challiss RA (2012). G protein-coupled receptor signalling in astrocytes in health and disease: a focus on metabotropic glutamate receptors. Biochem Pharmacol 84: 249-259.

Bruno V, Battaglia G, Casabona G, Copani A, Caciagli F, Nicoletti F (1998). Neuroprotection by glial metabotropic glutamate receptors is mediated by transforming growth factor-beta. J Neurosci 18: 9594-9600.

Bruno V, Battaglia G, Copani A, Giffard RG, Raciti G, Raffaele R et al (1995). Activation of class II or III metabotropic glutamate receptors protects cultured cortical neurons against excitotoxic degeneration. Eur J Neurosci 7: 1906-1913.

Bruno V, Copani A, Battaglia G, Raffaele R, Shinozaki H, Nicoletti F (1994). Protective effect of the metabotropic glutamate receptor agonist, DCG-IV, against excitotoxic neuronal death. Eur $J$ Pharmacol 256: 109-112.

Bruno V, Sureda FX, Storto M, Casabona G, Caruso A, Knopfel T et al (1997). The neuroprotective activity of group-II metabotropic glutamate receptors requires new protein synthesis and involves a glial-neuronal signaling. J Neurosci 17: 1891-1897.

Cahoy JD, Emery B, Kaushal A, Foo LC, Zamanian JL, Christopherson KS et al (2008). A transcriptome database for astrocytes, neurons, and oligodendrocytes: a new resource for understanding brain development and function. J Neurosci 28: 264-278.

Caraci F, Molinaro G, Battaglia G, Giuffrida ML, Riozzi B, Traficante A et al (2011). Targeting group II metabotropic glutamate (mGlu) receptors for the treatment of psychosis associated with Alzheimer's disease: selective activation of mGlu2 receptors amplifies beta-amyloid toxicity in cultured neurons, whereas dual activation of mGlu2 and mGlu3 receptors is neuroprotective. Mol Pharmacol 79: 618-626.

Casper KB, Jones K, McCarthy KD (2007). Characterization of astrocyte-specific conditional knockouts. Genesis 45: 292-299. 
Casper KB, McCarthy KD (2006). GFAP-positive progenitor cells produce neurons and oligodendrocytes throughout the CNS. Mol Cell Neurosci 31: 676-684.

Chavez-Noriega LE, Stevens CF (1994). Increased transmitter release at excitatory synapses produced by direct activation of adenylate cyclase in rat hippocampal slices. J Neurosci 14: 310-317.

Ciccarelli R, D'Alimonte I, Ballerini P, D'Auro M, Nargi E, Buccella S et al (2007). Molecular signalling mediating the protective effect of A1 adenosine and mGlu3 metabotropic glutamate receptor activation against apoptosis by oxygen/glucose deprivation in cultured astrocytes. Mol Pharmacol 71: $1369-1380$.

Ciccarelli R, Di Iorio P, Bruno V, Battaglia G, D'Alimonte I, D'Onofrio $\mathrm{M}$ et al (1999). Activation of A(1) adenosine or mGlu3 metabotropic glutamate receptors enhances the release of nerve growth factor and S-100beta protein from cultured astrocytes. Glia 27: 275-281.

Concas A, Santoro G, Mascia MP, Maciocco E, Dazzi L, Ongini E et al (1993). Anticonvulsant doses of 2-chloro-N6-cyclopentyladenosine, an adenosine A1 receptor agonist, reduce GABAergic transmission in different areas of the mouse brain. J Pharmacol Exp Ther 267: 844-851.

Corti C, Battaglia G, Molinaro G, Riozzi B, Pittaluga A, Corsi M et al (2007). The use of knock-out mice unravels distinct roles for mGlu2 and mGlu3 metabotropic glutamate receptors in mechanisms of neurodegeneration/neuroprotection. J Neurosci 27: 8297-8308.

de Mendonca A, Ribeiro JA (1994). Endogenous adenosine modulates long-term potentiation in the hippocampus. Neuroscience 62: 385-390.

Di Liberto V, Bonomo A, Frinchi M, Belluardo N, Mudo G (2010). Group II metabotropic glutamate receptor activation by agonist LY379268 treatment increases the expression of brain derived neurotrophic factor in the mouse brain. Neuroscience 165: 863-873.

Engers JL, Rodriguez AL, Konkol LC, Morrison RD, Thompson AD, Byers FW et al (2015). Discovery of a selective and CNS penetrant negative allosteric modulator of metabotropic glutamate receptor subtype 3 with antidepressant and anxiolytic activity in rodents. J Med Chem 58: 7485-7500.

Fujita T, Chen MJ, Li B, Smith NA, Peng W, Sun W et al (2014). Neuronal transgene expression in dominant-negative SNARE mice. J Neurosci 34: 16594-16604.

Galici R, Jones CK, Hemstapat K, Nong Y, Echemendia NG, Williams LC et al (2006). Biphenyl-indanone A, a positive allosteric modulator of the metabotropic glutamate receptor subtype 2, has antipsychotic- and anxiolytic-like effects in mice. J Pharmacol Exp Ther 318: 173-185.

Gereau RW, Conn PJ (1994a). Potentiation of cAMP responses by metabotropic glutamate receptors depresses excitatory synaptic transmission by a kinase-independent mechanism. Neuron 12: 1121-1129.

Gereau RWT, Conn PJ (1994b). Presynaptic enhancement of excitatory synaptic transmission by beta-adrenergic receptor activation. J Neurophysiol 72: 1438-1442.

Gereau RWT, Winder DG, Conn PJ (1995). Pharmacological differentiation of the effects of co-activation of beta-adrenergic and metabotropic glutamate receptors in rat hippocampus. Neurosci Lett 186: 119-122.

Gao V, Suzuki A, Magistretti PJ, Lengacher S, Pollonini G, Steinman MQ et al (2016). Proc Natl Acad Sci USA 113: 8526-8531.

Hemstapat K, Da Costa H, Nong Y, Brady AE, Luo Q, Niswender CM et al (2007). A novel family of potent negative allosteric modulators of group II metabotropic glutamate receptors. J Pharmacol Exp Ther 322: 254-264.

Kingston AE, O'Neill MJ, Bond A, Bruno V, Battaglia G, Nicoletti F et al (1999a). Neuroprotective actions of novel and potent ligands of group I and group II metabotropic glutamate receptors. Ann $\mathrm{N}$ $Y$ Acad Sci 890: 438-449.

Kingston AE, O'Neill MJ, Lam A, Bales KR, Monn JA, Schoepp DD (1999b). Neuroprotection by metabotropic glutamate receptor glutamate receptor agonists: LY354740, LY379268 and LY389795. Eur J Pharmacol 377: 155-165.

Laureys G, Clinckers R, Gerlo S, Spooren A, Wilczak N, Kooijman R et al (2010). Astrocytic beta(2)-adrenergic receptors: from physiology to pathology. Progr Neurobiol 91: 189-199.

Linden AM, Shannon H, Baez M, Yu JL, Koester A, Schoepp DD (2005). Anxiolytic-like activity of the mGLU2/3 receptor agonist LY354740 in the elevated plus maze test is disrupted in metabotropic glutamate receptor 2 and 3 knock-out mice. Psychopharmacology 179: 284-291.

Lu M, Wang B, Zhang C, Zhuang X, Yuan M, Wang H et al (2014). PQ-69, a novel and selective adenosine A1 receptor antagonist with inverse agonist activity. Purinergic Signal 10: 619-629.

Marek GJ (2010). Metabotropic glutamate2/3 (mGlu2/3) receptors, schizophrenia and cognition. Eur J Pharmacol 639: 81-90.

Moldrich RX, Aprico K, Diwakarla S, O'Shea RD, Beart PM (2002). Astrocyte $\mathrm{mGlu}(2 / 3)$-mediated cAMP potentiation is calcium sensitive: studies in murine neuronal and astrocyte cultures. Neuropharmacology 43: 189-203.

Murchison CF, Zhang XY, Zhang WP, Ouyang M, Lee A, Thomas SA (2004). A distinct role for norepinephrine in memory retrieval. Cell 117: 131-143.

Noetzel MJ, Gregory KJ, Vinson PN, Manka JT, Stauffer SR, Lindsley CW et al (2013). A novel metabotropic glutamate receptor 5 positive allosteric modulator acts at a unique site and confers stimulus bias to mGlu5 signaling. Mol Pharmacol 83: 835-847.

O'Dell TJ, Connor SA, Guglietta R, Nguyen PV (2015). betaAdrenergic receptor signaling and modulation of long-term potentiation in the mammalian hippocampus. Learn Mem 22: 461-471.

Ohishi H, Shigemoto R, Nakanishi S, Mizuno N (1993). Distribution of the mRNA for a metabotropic glutamate receptor (mGluR3) in the rat brain: an in situ hybridization study. J Comp Neurol 335: 252-266.

Orre M, Kamphuis W, Osborn LM, Melief J, Kooijman L, Huitinga I et al (2014). Acute isolation and transcriptome characterization of cortical astrocytes and microglia from young and aged mice. Neurobiol Aging 35: 1-14.

Otis JM, Werner CT, Mueller D (2015). Noradrenergic regulation of fear and drug-associated memory reconsolidation. Neuropsychopharmacology 40: 793-803.

Pitsikas N, Markou A (2014). The metabotropic glutamate 2/3 receptor agonist LY379268 counteracted ketamine-and apomorphine-induced performance deficits in the object recognition task, but not object location task, in rats. Neuropharmacology 85: 27-35.

Schmitt LI, Sims RE, Dale N, Haydon PG (2012). Wakefulness affects synaptic and network activity by increasing extracellular astrocyte-derived adenosine. J Neurosci 32: 4417-4425.

Sheffler DJ, Conn PJ (2008). Allosteric potentiators of metabotropic glutamate receptor subtype 1a differentially modulate independent signaling pathways in baby hamster kidney cells. Neuropharmacology 55: 419-427.

Taherian F, Vafaei AA, Vaezi GH, Eskandarian S, Kashef A, Rashidy-Pour A (2014). Propranolol-induced impairment of contextual fear memory reconsolidation in rats: a similar effect on weak and strong recent and remote memories. Basic Clin Neurosci 5: 231-239.

Tang WJ, Gilman AG (1991). Type-specific regulation of adenylyl cyclase by $G$ protein beta gamma subunits. Science 254: 1500-1503.

Walker AG, Wenthur CJ, Xiang Z, Rook JM, Emmitte KA, Niswender CM et al (2015). Metabotropic glutamate receptor 3 
activation is required for long-term depression in medial prefrontal cortex and fear extinction. Proc Natl Acad Sci USA 112: 1196-1201.

Wenthur CJ, Morrison R, Felts AS, Smith KA, Engers JL, Byers FW et al (2013). Discovery of (R)-(2-fluoro-4-((-4-methoxyphenyl) ethynyl)phenyl) (3-hydroxypiperidin-1-yl)methanone (ML337), an mGlu3 selective and CNS penetrant negative allosteric modulator (NAM). J Med Chem 56: 5208-5212.

Winder DG, Conn PJ (1993). Activation of metabotropic glutamate receptors increases cAMP accumulation in hippocampus by potentiating responses to endogenous adenosine. J Neurosci 13: 38-44.

Winder DG, Conn PJ (1995). Metabotropic glutamate receptor (mGluR)-mediated potentiation of cyclic AMP responses does not require phosphoinositide hydrolysis: mediation by a group II-like mGluR. J Neurochem 64: 592-599.

Winder DG, Ritch PS, Gereau RW, Conn PJ (1996). Novel glialneuronal signalling by coactivation of metabotropic glutamate and beta-adrenergic receptors in rat hippocampus. J Physiol 494 (Pt 3): 743-755.

Zhang JM, Wang HK, Ye CQ, Ge W, Chen Y, Jiang ZL et al (2003). ATP released by astrocytes mediates glutamatergic activitydependent heterosynaptic suppression. Neuron 40: 971-982.

Zhang Y, Chen K, Sloan SA, Bennett ML, Scholze AR, O'Keeffe S et al (2014). An RNA-sequencing transcriptome and splicing database of glia, neurons, and vascular cells of the cerebral cortex. J Neurosci 34: 11929-11947.

Supplementary Information accompanies the paper on the Neuropsychopharmacology website (http://www.nature.com/npp) 